\title{
Multi-level perspective to facilitate sustainable transitions - A pathway for German OEMs towards electric vehicles
}

\author{
Oliver Krätzig*
}

Helmholtz-Institute Münster, IEK-12 of Forschungszentrum Jülich GmbH, HI MS, Münster, Germany.

Institute of Business Administration at the Department of Chemistry and Pharmacy, University of Münster, Münster, Germany.

E-mail: o.kraetzig@fz-juelich.de

\section{Valeria Franzkowiak}

Institute of Business Administration at the Department of Chemistry and Pharmacy, University of Münster, Münster, Germany.

E-mail: v_fran03@uni-muenster.de

\section{Nathalie Sick}

Faculty of Engineering and IT, University of Technology Sydney,

Australia.

E-mail: nathalie.sick@uts.edu.au

* Corresponding author

\begin{abstract}
Sustainable transitions within industrial branches are a complex problem since they involve emerging technologies, as well as cultural, market and policy related changes. Recent studies emphasize the need for analytical approaches that not only do justice to this complexity by reflecting relevant trends and determinants, but also reveal insights that are intuitive enough to be implemented without major effort. Aiming at addressing this trade-off, we pursue a strategic analytical procedure that links external factors from a multilevel-perspective and internal, company-specific dynamic capabilities. We draw on expert interviews and subsequent qualitative analytical evaluation to obtain insights regarding individual motives, visions and boundary conditions of actors from the German automotive industry. Our contribution is both conceptually and practically important, as it unveils manifestations of significant dynamic capabilities and provides recommendations for change managers and policy makers leading to successful, sustainable transition in the automotive industry.
\end{abstract}

Keywords: multi-level perspective, resource based view, socio-technical transition, sustainable transition, automotive industry, electric vehicles, 


\section{Introduction}

Ambitious climate objectives emphasize, amongst others, the need to reduce the consumption of fossil fuels, local pollutants and noise emissions. Of specific importance is the initiative of the European Union regarding the introduction of emission standards creating a binding legal framework for the automotive industry and specifying that $\mathrm{CO}_{2}$ emissions have to be lowered to an average of $95 \mathrm{~g} / \mathrm{km}$ by 2020 (The European Union 2014). Another example for climate initiatives are China's ambitious goals regarding the promotion of New Energy Vehicles (NEVs), comprising battery electric vehicles (BEVs), plug-in hybrid electric vehicles (PHEVs) and fuel cells vehicles (FCVs). From 2019 onwards, manufacturers selling more than 30,000 cars in the People's Republic, have to participate in a credit system for NEVs. Companies that are unable to earn enough credits through the sale of NEVs must purchase credits, de facto amounting to a fine. According to a statement from the Chinese Ministry of Industry and Information Technology, the quotas will be raised again in 2020 (McDonald 2019). Since the transformation of the energy supply and utilisation of entire sectors is congruent with changing fundamental industrial, infrastructural and market-related conditions, tackling related challenges requires a long term innovation strategy capable of coping with such high complexity (Wallner 1999).

The substantial changes related to sustainable transitions are of high complexity since they not only comprise emerging technologies, but also cultural, market and policy related changes (Geels 2010). Policy makers and key stakeholders which actively promote sustainable transition need to face up to this complexity by addressing specific transition-related barriers based on lock-in mechanisms, which can manifest in sunk investment, patterns of behaviour or infrastructural condition (Unruh 2000). Therefore, there is a need for analytical approaches that not only do justice to this complexity by reflecting the relevant trends and influencing variables, but at the same time are intuitive enough to be applied without major effort.

A number of previous studies have addressed the phenomenon of industry transition based on the progress of sustainable technologies (Porter and van der Linde 1995; Rennings 2000). One step further towards gaining a deeper understanding of the nature of sustainable transition is the notion of technological transitions as evolutionary reconfiguration processes. This involves a change at different hierarchical levels, which, in addition to the technological niches, are termed sociotechnical regimes and superordinate sociotechnical landscapes. Analogous to evolution theories and their guiding idea of "variation and selection", the existing regime, i.e. the entity of established institutional structures, changes with the sociotechnical landscape and reveals potential for the application of innovations in technological niches (Geels 2002). A number of studies took up this concept and addressed the sustainable transition of the transport sector by examining the case of electric vehicles. For instance, systemic continuity in existing regimes as well as embedded social functions was previously explored (Wells and Nieuwenhuis 2012).

While difficulties related to sustainable transitions have been sufficiently studied from a conceptual and theoretical perspective, a concise investigation resulting in applicationoriented analytical approaches facilitating actions for practitioners and policy makers is still lacking in literature. Thus, we follow the call for more research on gaining a better 
understanding of the way that embedded practices and technological change influence each other (Wells and Nieuwenhuis 2012).

This paper examines the challenges of the German automotive industry and its transformation from ICVs to EVs by identifying relevant resources and capabilities for a successful transition to sustainable technologies. We introduce a strategic analytical approach based on a multi-level perspective, drawing on the resource-based view (RBV) and dynamic capabilities.

We identify political pressure, charging infrastructure, technological uncertainty and the increasingly changing value chain as the external factors with the greatest impact on the sustainable transition of the automotive industry. Experience of automotive industry's established actors in optimising mass production as well as well-spread distribution channels are emphasized as manifestations of adaptation dynamic capabilities. These have been identified as valuable for facilitating sustainable transition by advanced knowledge, resource exploitation and deployment. Major challenges are seen in accessing valuable new knowledge primarily from the field of IT and energy storage solutions as well as the acquisition of related cross-boundary management skills. Even more importantly, the need to promote innovation dynamic capabilities allowing for the development of unique skills and long-term competitive advantages is discussed.

The findings are both conceptually and practically important since they contribute to the further operationalization of sustainable transitions. This comprises of enriching existing knowledge on mostly volatile socio-technical structures within the setting of sustainable transitions through an in-depth qualitative study and thus contributing to a more solid foundation, especially for emerging fields with little data availability. We further add to the concept of multi-level perspective by elaborating on niche-regime interactions in the setting of sustainable transition. Drawing on literature from dynamic capabilities and organisational ambidexterity, we emphasize adequate reconfiguration of resources and capabilities as well as balancing of technological use as a path for incumbent sociotechnical regimes to successfully pass sustainable transition. Additionally, tangible ways in which these can manifest are demonstrated. Thus, we offer further practical implication by providing explicit recommendations for change managers and policy makers that can lead to successful sustainable transition in the automotive industry.

The remaining article is structured as follows: Section 2 gives an overview of previous approaches in the literature to structuring and obtaining insights into sustainable transitions. Section 3 describes the process of data collection and evaluation, while results and discussion of the study are presented in section 4. Finally, section 5 highlights contributions, practical implications and limitations as well as recommendations for future research.

\section{Theoretical background}

\subsection{Multi-level perspective framework to disentangle sustainable transitions}

Over the course of history, countless technological innovations have been created and have since become an essential part of research in the field of innovation management (Schumpeter 1934). New technologies are developed and coexist with incumbent ones 
before they are replaced. These can include, for instance, technologies ranging from sailing ships to steamships and from transportation relying on horsepower to automobiles in the transport sector (Geels 2002; Sick et al. 2016; van Bree et al. 2010).

Based on evolutionary economics, technological transitions describe how technological innovations take place and are integrated into society (Evans 2012). In addition to technological advances, however, technological change is accompanied by far-reaching social changes in terms of use, regulation, structure or culture (Geels 2002). The relevant literature refers to the "seamless network", which thematizes the integration of technologies on the basis of intersections with physical objects, organizations, scientific communities and social units (Douglas et al. 2012). Exploring how and in what way such a transition takes place, studies propose that innovations which support change can develop in protected niches until they are taken up by established structures consisting of industry, associations as well as other institutions. Strategic niche management is promising for the promotion of high-potential technologies in the future (Kemp et al. 1998).

To gain an understanding of the multi-dimensional complexity of sustainability transitions, the multi-level perspective (MLP) framework is a suitable analytical tool (Geels 2010; Smith et al. 2010). In the context of MLP, transitions are perceived as evolutionary reconfiguration processes that address change at different hierarchical levels. These levels, in addition to technological niches, also encompass sociotechnical regimes and superordinate sociotechnical landscapes and are capable of offering different explanatory insights for understanding sustainable transition (Figure 1) (Geels 2002; Moradi and Vagnoni 2018). While the multi-level perspective allows for a differentiation of socio-technical systems on the basis of their degree of granularity (from broad to narrow), the procedural perspective for the realization of transition is described by interaction processes of involved actors.

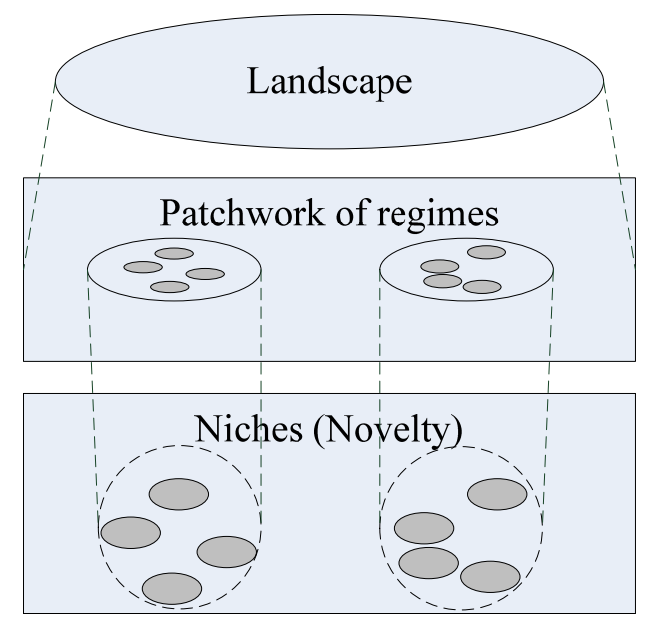

Figure 1 Multiple levels applied in MLP as a nested hierarchy.

Source: Adapted from (Geels 2002).

However, the framework is subject to criticism, mainly for its lack of operationalization, manifesting in fundamental discussions about the interactions of the individual levels and 
their transition-initiating mechanisms. Thus, an overemphasis on technological niches is criticized as well as the potential for change from reforms to the established regimes (Smith et al. 2005). Subject to further criticism are the methodological comprehensibility and interpretability of MLP findings (Genus and Coles 2008). From these points of criticism, a number of novel lines of research emerge, highlighting the need for investigations on niche dynamics, unlocking regimes as well as the influence of spatial aspects of transitions, methods for transition mapping and political regulation (Genus and Coles 2008; Smith et al. 2010). In particular, further insights on unlocking regimes are promising in order to contribute to solving the problem of how established regimes can be prepared for change towards sustainable technologies without experiencing serious consequences. Approaches include the investigation of appropriate conditions of the political economy, such as the balance of power, change of political movements or institutional development, and aim at answering fundamental questions about the opening, erosion and decay of regimes (Smith et al. 2010). Another line of research for the development of regimes is concerned with roles and strategies of individual actors within these processes. This strand of literature is promising to overcome MLP's criticized lack of operationalization by identifying success factors of individual actors for an effective sustainable transition (Duygan et al. 2019; Roberts and Geels 2019). In this context, the necessary corporate resources and capabilities to keep competitive advantages in a particularly volatile environment seem to be a complementary perspective for the operationalization of MLP.

\subsection{Operationalizing MLP via dynamic capabilities}

The link between corporate resources and sustainable competitive advantage, itself driven by innovation in the case of high-tech industries, is associated with the literature regarding the RBV (Barney 1991). Capabilities represent corporate resources which are described as "a special type of resource-specifically, organizationally embedded nontransferable firm-specific resource whose purpose is to improve the productivity of the other resources possessed by the firm" (Teece et al. 1997). While the mechanism of resource picking according to the RBV is generally concerned with collecting information and performing analyses in order to optimize the available resources and respond to the resource market, the development of organizational systems in the context of market dynamics and change is emphasized according to the concept of dynamic capabilities. Dynamic capabilities aim at promoting the development of capabilities which are appropriate to increase the productivity of (acquired) corporate resources (Teece et al. 1997). According to these mutually complementary properties, the two mechanisms (RBV and dynamic capabilities) are generally used in parallel by companies in which they partly complement each other, but may also replace each other (Makadok 2001).

In the context of technological transitions, emphasis is placed on "adaptation dynamic capabilities", which describe processes for optimized resource exploitation and deployment (Helfat and Peteraf 2009; March 1991) and on "innovation dynamic capabilities", referring to the development of entirely new capabilities via exploration and path-creation processes (Dixon et al. 2014; Garud and Karnøe 2001; March 1991). Interestingly, Teece also uses the term of "reconfiguration" - however, of specific abilities - to illustrate that actors who manage to successfully deal with transition possess 
specific characteristics. In other words, this relates to resources that are not only suitable in fostering innovation, but also to adapt to changing environments (Teece 2007).

Exemplary manifestations of organizational design for digital transformation based on relevant dynamic capabilities emphasize agility as a key characteristic for the strategic renewal of business models, collaboration and corporate culture (Warner and Wäger 2019). These dynamic capabilities also represent an important foundation for the operationalisation of MLP's core concepts, since only few analytical rules have been elaborated so far and thus allowing for a thorough understanding of the complex configurations and the abstraction of an objective socio-technical system (Genus and Coles 2008). Further operationalisation of MLP is generally associated with approaches to limiting, dividing and organising the system. Due to the relatively young character of this line of research, most studies apply an emergent and reflexive research style and make use of qualitative methods in order to identify patterns of further formalization of MLP for sustainable transitions (Smith et al. 2010).

Previous research pointed out that there is great potential to contribute to solve delicate and chaotic strategic problems through the complementary and integrated use of demandoriented perspectives, such as MLP, with perspectives focussing on individual actors including the RBV (Priem and Butler 2001). Despite its potential for multi-facetted and demand-oriented analysis for sustainable transition, a combined approach of MLP and RBV has not yet been sufficiently addressed by existing literature. One possible reason may be the scarcity of data, especially for sustainable transitions, since such long-term macro-systemic changes are rare and often exclude unstable socio-technical situations (Smith et al. 2010). However, we see great potential in the combination of analytical approaches related to changing socio-technical environment and company-internal resources in order to also meet the outstanding research efforts of formalising MLP into more detailed methods (Haxeltine et al. 2008).

\section{Methodology for data collection and evaluation}

Since qualitative expert studies are particularly suitable to access and understand individual motives, visions and boundary conditions (Buonansegna et al. 2014; Hansen et al. 2009; Sabatier et al. 2012), we draw on semi-structured expert interviews as well as written expert statements to get in-depth insights from the German automotive industry. The sustainable transition of the automotive sector towards the use of renewable energies is receiving a considerable amount of attention from politics and society. This is certainly not only due to its economic relevance (The Federal Statistical Office 2017), but also due to its accessibility through familiarity with the automobile as a product and societal status symbol. Efforts related to the transition of the automotive industry aim at creating transportation solutions, which are compatible for an energy supply out of renewable energy sources. As such, solutions primarily revolving around electric drive trains with energy supply from batteries or fuel cells are emphasized. For research design as well as data collection and analysis, a structured procedure is followed (Figure 2). 


\begin{tabular}{|c|}
\hline $\begin{array}{l}\text { Preparing a qualitative study } \\
\text { - Defining relevant interview participants } \\
\text { - Developing a research questionnaire based on prior literature review } \\
\text { - } \quad \text { Collecting contact data of relevant interview participants }\end{array}$ \\
\hline$\nabla$ \\
\hline $\begin{array}{l}\text { Data Collection } \\
\text { - Contacting and acquisition of interviewees via E-Mail and LinkedIn } \\
\text { - Conducting Interviews } \\
\text { - Interview transcription }\end{array}$ \\
\hline$\nabla$ \\
\hline $\begin{array}{l}\text { Data Analysis } \\
\text { - Data evaluation according to qualitative content analysis by Mayring } \\
\text { with the aid of MAXQDA } \\
\text { - Classification of the results according to the MLP structure } \\
\text { - Identification of dynamic capabilities, operationalizing MLP }\end{array}$ \\
\hline
\end{tabular}

Figure 2 Sequential process of shaping the research design, as well as data collection and analysis.

Source: Own figure.

We draw on a sample of expert insights, which is particularly comprehensive, as it not only reflects the original equipment manufacturer (OEM) perspective, but also includes different positions of the automotive value chain from its relevant environment. We consolidate perceptions of experts from the professional positions of research and development, OEMs, suppliers, consultancies, public institutions and industry associations. All experts had a relation to the German automotive industry and the subject of electric mobility as part of their professional background, enabling us to derive conclusions which are not biased by field of proficiency. In total, the present study is based on a number of 18 expert statements, which provide a suitable representation of perspectives on German automotive industry. We were particularly interested in experts' insights on the drivers of change, assessments of the relevance of environment conditions (technological uncertainty, industry, infrastructure), market conditions, business capabilities and strategies which help explain inhibiting factors for transition and shape recommendations to facilitate a sustainable transition to EVs (Table 1) (Carlsson et al. 2002; Geels 2010; Levinthal 1992; Malerba 2002; Markard and Truffer 2008).

An interview guideline was prepared on the basis of a thorough literature review. In order to validate the interview guideline, pre-test interviews were conducted with two interview candidates in advance. After recording the semi-structured interviews, a transcription of the audio files to text files was performed for reasons of ensuring reliability (Bourgeois and Eisenhardt 1988). The subsequent evaluation of the collected interview and written data is based on a qualitative content analysis approach, itself based on a deductive development of coding categories (Mayring 2014). The coded data from our empirical investigation was, in a final step, used to combine the disclosed external and internal influencing factors of sustainable transition for German automotive industry, providing a basis for deriving strategies and recommendations to facilitate successful sustainable transition. 
Table 1 Number and professional background of the interviewees

\begin{tabular}{lc} 
Description & Number \\
\hline Consultancies with a focus on sustainable mobility solutions & 2 \\
Consultancies with a focus on the automotive industry & 3 \\
Industry associations & 3 \\
Suppliers of the automotive industry & 2 \\
Automotive industry & 2 \\
Public agencies for the advancement of innovations & 3 \\
Research institutions & 3 \\
\hline Sum & 18 \\
\hline
\end{tabular}

Source: Own table.

\section{Findings and discussion}

\subsection{External determinants of automotive industry's sustainable transition}

In line with former studies, findings from the MLP indicate that besides the pressure on OEMs, exerted by successful market entrants from China and the US, the speed of the transition to EVs is primarily dependent on the amount of political and regulatory pressure (Berkeley et al. 2017) (Figure 3). For German OEMs, political agreements regarding climate protection operate as a key driver for the transition towards sustainable technologies.

The development towards a comprehensive charging infrastructure still requires substantial effort. However, the majority of interviewees shared the view that there is promising development, manifesting in governmental funding and emerging collaborations such as the joint-venture IONITY from Volkswagen, Daimler, BMW and Ford, aiming to facilitate the establishment of an effective charging infrastructure along European main routes.

Interviewees highlighted the announced accelerated introduction of new vehicle models by manufacturers and the credibility of these announcements. This implies that established companies in the automotive industry have taken up the issue of electric mobility and consider it an integral part of their operations. Furthermore, the transformation of the automotive industry is also seen as an opportunity, according to which the operation of a charging infrastructure and an activity in the development of battery cells is, under certain circumstances, to be regarded as attractive as opposed to threatening.

The interviewees said that the value chain of the automotive industry is changing profoundly with BEVs, since, in line with other studies (Le Petit 2017), BEVs enable new vehicle architectures that require different production processes and ultimately a different value chain. All respondents noted that battery technology was the most important value-adding component in EVs. Due to the changes in the value chain, 
companies focussing on internal combustion engines and the corresponding powertrains will be most affected by the shift to EVs and are potentially forced to define a new corporate mission-to reinvent their business model and to develop a new business strategy. New players will become determining in the automotive value chain, e.g. hightech companies such as Samsung will play an important role as tier-one automotive supplier for BEVs. This allows newcomers, such as players from China, to enter the automotive market. As highlighted by the interviewees, China takes a leading role in establishing EVs and further exploiting related technological opportunities. However, an imminent threat by new rivalry from Chinese corporations is not feared, since trade barriers are more likely to lead to a parallel development.

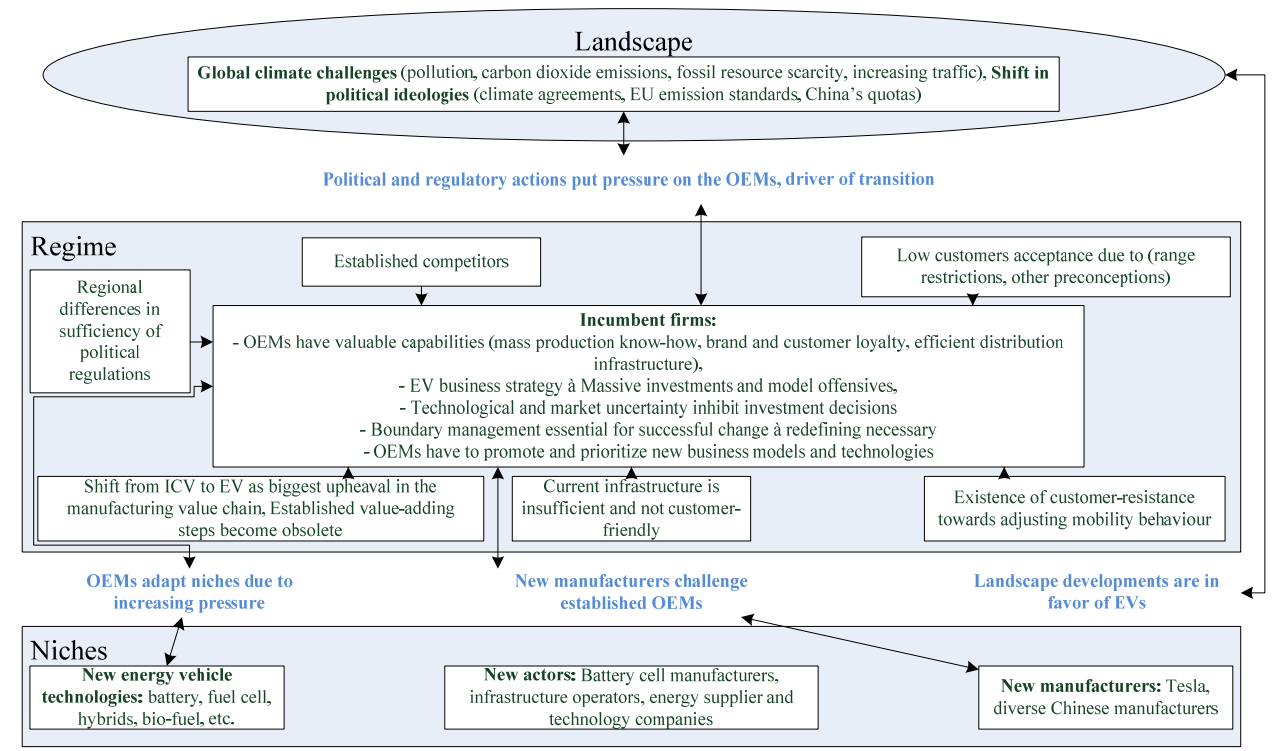

Figure 3 A multi-level-perspective on transitions within automotive industry. Source: Modified from (Geels 2002).

We emphasize the role of technological uncertainty as significant as it affects all actors involved in the transition process and poses a barrier to decisions in favour of EVs for customers, manufacturers and other parties alike. Respondents pointed out that the uncertainties originate from the extraction of critical raw materials such as lithium and copper as well as the development of electricity and battery prices. The interviewees stated that there is a variety of technological limitations of BEVs that have to be dealt with and cause a lower customer acceptance than for conventional automobiles. However, the general technological progress enabling for higher distances and lower costs of EVs counteracts this and leaves a positive impression.

Some of the experts assessed electric mobility as just one part of a transition to sustainable mobility. The actors (especially politics) could decide to promote the coexistence of multiple drive technologies, perhaps pushing FCVs in the future. While all interviewees agreed on the potential of BEVs, they agreed that there is still quite some uncertainty with regard to which drive technology will prevail for which use cases. 


\subsection{Corporate capabilities and challenges for successful sustainable transition}

A capability of decisive importance for the transition to sustainable technologies of established players in the automotive industry is the scalability of production processes. New players such as Tesla Inc. have enormous difficulties with establishing mass production of their vehicles and lose potential profit as a result (Kolodny 2018). Interviewees and further reports confirmed that established OEMs have experience and deep knowledge in vehicle mass production which is also suitable to be transferred to the manufacturing of EVs - including battery cell production (Küpper et al. 2018). Scalability unfolds its full effect specifically during the implementation of new business models in the transition of the automotive industry, which are closely linked to dynamic capabilities and strategies. While individual technologies can be protected by patents or trade secrets, in order to gain a large market share from new business models, a fast process-related implementation is required that goes hand in hand with fast learning ability and scalability. After a successful implementation, switching costs to promote customer lock-in effects can be established in accordance to the business model in order to raise entry barriers for potential competitors (Teece 2018).

In addition to scalability, targeted market segmentation and an appropriate marketing strategy are crucial for successful transition. OEMs have established a wide distribution network over the years to introduce new models to the market quickly. They also have known and strong brands that are trusted by customers. This grown marketing competence of established OEMs is certainly helpful in eliminating customer concerns regarding EVs, which are primarily related to the short range and high costs of EVs. Customer preconceptions about EVs lag behind the development of their actual most recent technological progress. Several surveys come to similar conclusions on the levels of acceptance. Ziefle et al. conclude that the comfort of traditional cars is still perceived as much higher than that of EVs (Ziefle et al. 2014). In a study by McKinsey, the authors emphasize that it is important for manufacturers of EVs to address these existing customer concerns. The authors' state "Effective communication/ marketing to address consumer concerns and the true benefits of EVs (e.g., reliability, charging convenience, performance) is critical to drive higher e-mobility adoption " (Knupfer et al. 2017).

Reflecting on our findings, we observe that the German automotive industry is in a good position for leading the transition to sustainable technologies, as it can draw on established and professionally developed structures and processes. Hence, dynamic capabilities for adapting and exploiting technological knowledge are particularly prevalent. This poses an important prerequisite for the generation, processing and integration of valuable knowledge and resources. Nevertheless, the German automotive industry has to face challenges related to the development of dynamic capabilities on exploring new business models resulting out of emerging technological opportunities and ways of fostering corporate implementation. Particularities are summarized in Table 2Error! Reference source not found. and explained in more detail in the following.

Apart from the ability to implement with pace, a prerequisite for successfully coping with sustainable transition is the ability of actors to learn quickly and comprehensively in a volatile environment (Teece 2018). Established actors from the automotive industry should therefore critically examine whether their processes, routines and structures could be optimised with regard to the absorption of cross-industrial and generally external 
knowledge (Dixon et al. 2007), where the integration of formerly unrelated knowledge is particularly noteworthy. As a result of the transition in the automotive industry, industry borders are shifting and new fields (including battery cell production, charging infrastructure and mobility services) are increasingly becoming important. This poses challenges for the automotive industry since important aspects of current mobility services are completely new to OEMs, e.g. many on-demand transactions with customers instead of mass-scale vehicle sales. OEMs must consider, how they can gain access to knowledge in these increasingly important fields. Firms also have to decide what they can access and produce in-house and to what extent they have to source from partners. As providers of holistic mobility solutions and services, OEMs increasingly have to cooperate with companies from outside the automotive industry, especially in the areas of innovative product solutions and information and communication technologies (ICTs). This is particularly the case in the fields of software development and digital products where OEMs do not traditionally possess the strongest in-house knowledge. Accenture highlights in a study that partnerships with digital companies are often the best way to gain access to capabilities in these areas (Schmidt et al. 2018). In addition, such collaborations offer the best way to scale up platforms and service offerings fast enough to reach a critical size. Therefore, interviewees recommend the engagement of OEMs in cross boundary management, especially in the areas of innovative product solutions and ICTs, as promising for dealing with the transition to EVs.

Table 2 Identified key capabilities and challenges for successful sustainable transition of German OEMs.

\begin{tabular}{ll}
\hline Capabilities of OEMs & Challenges \\
\hline \multicolumn{1}{c}{ Adaptation (Exploitation and Deployment) } & \\
\hline $\begin{array}{l}\text { Distinct ability to scale production processes } \\
\text { Grown marketing competences and broad } \\
\text { distribution network }\end{array}$ & $\begin{array}{l}\text { Optimization of routines and structures for the } \\
\text { absorption of external knowledge / cross- } \\
\text { boundary management }\end{array}$ \\
\hline \multicolumn{1}{c}{ Innovation (Exploration and Path Creation) } & $\begin{array}{l}\text { Opportunity for in-house development of } \\
\text { problem solutions through experimentation and } \\
\text { conscious deviation from known paths to } \\
\text { develop unique capabilities }\end{array}$ \\
$\begin{array}{l}\text { Established routines of innovation management } \\
\text { and grown R\&D competence }\end{array}$ & \begin{tabular}{l} 
Management of organizational ambidexterity \\
\hline
\end{tabular}
\end{tabular}

Source: Own table.

In addition to the required structures for leveraging existing competencies, it is above all concepts of creativity, business model innovation and intrapreneurship that have received less attention according to our findings. Of course, this can be explained by our interviewees not being directly involved in these processes. However, it nevertheless indicates a general deficit regarding the innovation culture of the automotive industry, as it should be a concern to perceive innovation as a cross-departmental, holistic task. Therefore, there is an even greater challenge in developing innovation dynamic capabilities that are suitable for developing new paths and business models with the goal of realizing competitive advantages (Dixon et al. 2014). According to an ideal-typical 
process, it is first necessary to identify a problem by applying creativity approaches and to develop ideas for its solution. Companies should then check whether they have provided sufficient resources and routines in order to be able to thoroughly experiment, advance and optimize the problem-solving solutions. Finally, the implementation of proven ideas must take place within routine innovation processes. Here, the internal development of problem solutions through experimentation and the conscious deviation from existing knowledge is essential for companies to develop unique capabilities (Garud and Karnøe 2001). Thus, the creation of new routines (not just the importation of routines from others) proves particularly important (Kogut and Zander 1996). These gained unique capabilities have greater prospects in not being directly imitated by competitors and can therefore be further developed into competitive advantages that are desirable for the automotive industry aiming at successful transition to sustainable technologies. A concern of considerable importance for managers should therefore be to grant an appropriate amount of resources for the development of corporate innovation capabilities and routines. Hence, they need to face the challenges of overcoming general risk aversion as well as establishing a purposeful acceptance of failure.

In order to achieve desirable (as stated by some interviewees) flexibility and agility of development and production processes being in line with appropriately adapted innovation processes, strategies for managing organisational ambidexterity, i.e. to cope with tasks associated with exploration and exploitation of knowledge and resources, are required. Standard strategies for the automotive industry in the context of structural ambidexterity are, for example, the formation of organizational subsystems that exclusively focus on EVs or EV-related subjects to remain competitive in the mature market for ICVs and to avoid obstructive competition between these two fields of activity (Adler et al. 1999; McDonough and Leifer 1983; Tushman and O'Reilly 1996). Considering a less developed and pronounced innovation culture in certain corporations of the automotive industry, it is feasible to separate some corporate functions according to the structural ambidexterity approach, or to transform the corporate innovation culture according to the contextual ambidexterity approach (Gibson and Birkinshaw 2004; McCarthy and Gordon 2011). Current research provides recommendations on how to place entrepreneurially trained personnel in key positions within the company with an affinity for innovation in order to promote such a transformation (Sagmeister 2019).

\section{Conclusion}

In order to allow for a facilitated access to the complex problem of sustainable transition for the automotive industry, we develop and validate a strategic analytical approach within the scope of this study. We identify established routines of innovation management and grown $\mathrm{R} \& \mathrm{D}$ competences as well as previous experience in optimising mass production and the availability of established distribution channels as important capabilities for successful sustainable transitions. We also identified major challenges for the automotive industry in establishing a commitment to cross-boundary management in promoting in-house development of problem solutions by experimenting and consciously deviating from known paths leading to the development of unique capabilities, as well as in promoting concepts for the management of organisational ambidexterity. Furthermore, 
political pressure, the development of a charging infrastructure, technological uncertainty and the evolving value chain are decisive external determinants.

By introducing an analytical approach which links the multi-level perspective for unveiling external determinants relevant to sustainable transition to company-specific capabilities, we contribute to the research stream on empirical operationalization of sustainable transitions in two ways. First, we contribute to the methodical formalisation of MLP by further elaborating on niche-regime interaction's theoretical foundation. We elaborate on the relationship of MLP literature to perspectives of dynamic capabilities and organizational ambidexterity by describing them as a theoretical foundation for evolutionary reconfiguration processes of corporate resources and capabilities and management practices that are capable of overcoming lock-in mechanisms of companies in existing socio-technical regimes. Second, by drawing on the example of transition in the automotive industry from ICVs to EVs, we reinforce the suitability of MLP to increase the understanding of such socio-technical transition. We also enrich existing knowledge on mostly unstable socio-technical situations within the setting of sustainable transitions through adding an in-depth qualitative study. Thus, we contribute to a more solid foundation especially for emerging fields with little data availability. Our contribution to the literature strand of empirical operationalization also comes along with a reflexive character (Loorbach 2007), which directly provides practical implications through the insights gained.

Our study provides practical implications for innovation managers within the automotive industry who are responsible for the transition towards EVs. Research managers can reduce the risk of a further commoditization of vehicle manufacturing, due to the changing value chain induced by EVs, by acquiring valuable new knowledge from various fields of industry. Specifically, it is referred to knowledge from the fields of battery manufacturing and IT technology, which are promising to enable new vehicle design, manufacturing and specific mobility services, needed for a highly connected transportation infrastructure in the future. In addition, the establishment of new partnerships offers an alternative approach to follow, since partnerships with partners possessing complementary competencies offer the potential to move beyond traditional industry boundaries. However, it is precisely the internal development of problem solutions through experimentation and conscious deviation from existing approaches that should be sensitised, so that established actors from the automotive industry are able to develop "innovation dynamic capabilities" that potentially lead to competitive advantages in the long term. We emphasize the need to keep development and production processes sufficiently flexible and agile to successfully respond to the acceleration of innovation processes and competitor moves. Strategies are required to deal with organisational ambidexterity, i.e. to fulfil tasks associated with exploration and exploitation of knowledge and resources. Thus, we recommend companies pursue the strategy of forming organizational subsystems that exclusively focus on EVs or EV-related subjects to remain competitive in the mature market for ICVs and to avoid obstructive competition between these two fields of activity (following structural ambidexterity). As an alternative approach, pursuing contextual ambidexterity, the employment of innovation-oriented personnel at appropriate positions is recommended. Our insights can also be helpful for policy makers to uncover the needs of OEMs related to public responsibilities, such as standardization and building a charging infrastructure. These 
could profitably contribute to ensure the competitiveness of OEMs in the field of EVs through the use of new business models.

The current study pursues a qualitative research approach based on 18 expert interviews. According to the character of qualitative studies the approach aims at compiling specific in-depth expert knowledge. The main limitation of this approach lies in a rather small sample size which complicates the generalization of the findings in, for example, across industry boundaries. Another limitation of the present study relates to the national limitation of the qualitative database addressing the case German automotive industry. Although this can be justified by the fact that for hardly any other country is the automotive industry of such economic relevance for its national economy as for Germany, cross-national studies could lead to further solutions for the successful implementation of sustainable change in the automotive industry. Such studies could also shed further light on the influence of external factors such as political regulations and subsidy programmes for successful transitions. In order to assess the importance of different company-specific dynamic capabilities for sustainable industry transition, quantitative studies would certainly add value, allowing for a comprehensive overview of the industry through large scale analyses.

\section{References}

Adler, PS, B Goldoftas and DI Levine, (1999). Flexibility Versus Efficiency?: A Case Study of Model Changeovers in the Toyota Production System. Organization Science, 10(1), 43-68.

Barney, J, (1991). Firm Resources and Sustained Competitive Advantage. Journal of Management, 17(1), 99-120.

Berkeley, N, D Bailey, A Jones and D Jarvis, (2017). Assessing the transition towards Battery Electric Vehicles: A Multi-Level Perspective on drivers of, and barriers to, take up. Transportation Research Part A: Policy and Practice, 106, 320-332.

Bourgeois, LJ and KM Eisenhardt, (1988). Strategic Decision Processes in High Velocity Environments: Four Cases in the Microcomputer Industry. Management Science, 34(7), 816-835.

Buonansegna, E, S Salomo, AM Maier and J Li-Ying, (2014). Pharmaceutical new product development: Why do clinical trials fail? R\&D Management, 44(2), 189202.

Carlsson, B, S Jacobsson, M Holmén and A Rickne, (2002). Innovation systems: Analytical and methodological issues. Research Policy, 31(2), 233-245.

Dixon, S, K Meyer and M Day, (2014). Building Dynamic Capabilities of Adaptation and Innovation: A Study of Micro-Foundations in a Transition Economy. Long Range Planning, 47(4), 186-205.

Dixon, SE, KE Meyer and M Day, (2007). Exploitation and exploration learning and the development of organizational capabilities: A cross-case analysis of the Russian oil industry. Human Relations, 60(10), 1493-1523.

Douglas, DG, TP Hughes, TJ Pinch and WE Bijker, (2012). The social construction of technological systems: New directions in the sociology and history of technology Anniversary ed. MIT Press, Cambridge, Mass.

Duygan, M, M Stauffacher and G Meylan, (2019). A heuristic for conceptualizing and uncovering the determinants of agency in socio-technical transitions. Environmental Innovation and Societal Transitions.

Evans, JP, (2012). Environmental Governance. Routledge, London, UK. 
Garud, R and P Karnøe, (2001). Path Creation as a Process of Mindful Deviation. In: R Garud and P Karnøe, eds. Path dependence and creation. Psychology Press, New York, 1-40.

Geels, FW, (2002). Technological transitions as evolutionary reconfiguration processes: A multi-level perspective and a case-study. Research Policy, 31(8-9), 1257-1274.

Geels, FW, (2010). Ontologies, socio-technical transitions (to sustainability), and the multi-level perspective. Research Policy, 39(4), 495-510.

Genus, A and A-M Coles, (2008). Rethinking the multi-level perspective of technological transitions. Research Policy, 37(9), 1436-1445.

Gibson, CB and J Birkinshaw, (2004). The Antecedents, Consequences, and Mediating Role of Organizational Ambidexterity. Academy of Management Journal, 47(2), 209-226.

Hansen, EG, F Grosse-Dunker and R Reichwald, (2009). Sustainability Innovation Cube - A Framework to evaluate sustainability-oriented innovations. International Journal of Innovation Management, 13(04), 683-713.

Haxeltine, A, L Whitmarsh, N Bergman, J Rotmans, M Schilperoord and J Kohler, (2008). A Conceptual Framework for transition modelling. International journal of innovation and sustainable development, 3(1), 93.

Helfat, CE and MA Peteraf, (2009). Understanding dynamic capabilities: Progress along a developmental path. Strategic Organization, 7(1), 91-102.

Kemp, R, J Schot and R Hoogma, (1998). Regime shifts to sustainability through processes of niche formation: The approach of strategic niche management. Technology Analysis \& Strategic Management, 10(2), 175-198.

Knupfer, S, R Hensley, P Hertzke and P Schaufuss, (2017). Electrifying insights: How automakers can drive electrified vehicle sales and profitability, https://www.mckinsey.com/industries/automotive-and-assembly/ourinsights/electrifying-insights-how-automakers-can-drive-electrified-vehicle-salesand-profitability.

Kogut, B and U Zander, (1996). What Firms Do?: Coordination, Identity, and Learning. Organization Science, 7(5), 502-518.

Kolodny, L, (2018). Tesla factories reportedly struggling with high scrap volume, and low vehicle production rate per employee, https://www.cnbc.com/2018/06/05/teslafactories-have-struggled-with-scrap-production-rate-reports.html.

Küpper, D, K Kuhlmann, S Wolf, C Pieper, G Xu and J Ahmad, (2018). The Future of Battery Production for Electric Vehicles, https://eusmartcities.eu/sites/default/files/2018-10/BCG-The-Future-of-Battery-Productionfor-Electric-Vehicles-Sep-2018\%20\%281\%29_tcm81-202396.pdf.

Le Petit, Y, (2017). How will electric vehicle transition impact EU jobs?, https://www.transportenvironment.org/sites/te/files/publications/Briefing\%20$\% 20$ How $\% 20$ will\%20electric\%20vehicle\%20transition\%20impact\%20EU\%20jobs. pdf.

Levinthal, D, (1992). Surviving Schumpeterian Environments: An Evolutionary Perspective. Industrial and Corporate Change, 1(3), 427-443.

Loorbach, D, (2007). Transition management. New mode of governance for sustainable development. Utrecht: International Books.

Makadok, R, (2001). Toward a synthesis of the resource-based and dynamic-capability views of rent creation. Strategic Management Journal, 22(5), 387-401.

Malerba, F, (2002). Sectoral systems of innovation and production. Research Policy, $31(2), 247-264$.

March, JG, (1991). Exploration and Exploitation in Organizational Learning. Organization Science, 2(1), 71-87. 
Markard, J and B Truffer, (2008). Technological innovation systems and the multi-level perspective: Towards an integrated framework. Research Policy, 37(4), 596-615.

Mayring, P, (2014). Qualitative content analysis: theoretical foundation, basic procedures and software solution. SSOAR - Open Access Repository, Klagenfurt.

McCarthy, IP and BR Gordon, (2011). Achieving contextual ambidexterity in R\&D organizations: A management control system approach. R\&D Management, 41(3), 240-258.

McDonald, T, (2019). China powers up electric car market, https://www.bbc.com/news/business-46745472.

McDonough, EF and R Leifer, (1983). Using Simultaneous Structures to Cope With Uncertainty. Academy of Management Journal, 26(4), 727-735.

Moradi, A and E Vagnoni, (2018). A multi-level perspective analysis of urban mobility system dynamics: What are the future transition pathways? Technological Forecasting and Social Change, 126, 231-243.

Porter, M and C van der Linde, (1995). Green and Competitive: Ending the Stalemate. Harvard Business Review.

Priem, RL and JE Butler, (2001). Is the Resource-Based "View" a Useful Perspective for Strategic Management Research? Academy of Management Review, 26(1), 22-40.

Rennings, K, (2000). Redefining innovation - eco-innovation research and the contribution from ecological economics. Ecological Economics, 32(2), 319-332.

Roberts, C and FW Geels, (2019). Conditions and intervention strategies for the deliberate acceleration of socio-technical transitions: Lessons from a comparative multi-level analysis of two historical case studies in Dutch and Danish heating. Technology Analysis \& Strategic Management, 31(9), 1081-1103.

Sabatier, V, A Craig-Kennard and V Mangematin, (2012). When technological discontinuities and disruptive business models challenge dominant industry logics: Insights from the drugs industry. Technological Forecasting and Social Change, 79(5), 949-962.

Sagmeister, V, (2019). Impact of entrepreneurial employees on entrepreneurial orientation and strategic renewal, XXX ISPIM Innovation Conference, Florence.

Schmidt, A, J Reers and A Gerhardy, (2018). Mobility as a service: Mapping a route towards future success in the new automotive ecosystem,

https://www.accenture.com/_acnmedia/Accenture/ConversionAssets/DotCom/Documents/Global/PDF/Dualpub_26/Accenture-Mobility-As-aService.pdf.

Schumpeter, J, (1934). The Theory of Economic Development: An Inquiry into Profits, Capital, Credit, Interest, and the Business Cycle.

Sick, N, A-M Nienaber, B Liesenkötter, N Vom Stein, G Schewe and J Leker, (2016). The legend about sailing ship effects - Is it true or false?: The example of cleaner propulsion technologies diffusion in the automotive industry. Journal of Cleaner Production, 137, 405-413.

Smith, A, A Stirling and F Berkhout, (2005). The governance of sustainable sociotechnical transitions. Research Policy, 34(10), 1491-1510.

Smith, A, J-P Voß and J Grin, (2010). Innovation studies and sustainability transitions: The allure of the multi-level perspective and its challenges. Research Policy, 39(4), 435-448.

Teece, DJ, (2007). Explicating dynamic capabilities: The nature and microfoundations of (sustainable) enterprise performance. Strategic Management Journal, 28(13), 13191350 .

Teece, DJ, (2018). Business models and dynamic capabilities. Long Range Planning, $51(1), 40-49$. 
Teece, DJ, G Pisano and A Shuen, (1997). Dynamic capabilities and strategic management. Strategic Management Journal, 18(7), 509-533.

The European Union, (2014). Regulation (EU) No 333/2014 of the European Parliament and of the Council of 11 March 2014 amending Regulation (EC) No 443/2009 to define the modalities for reaching the 2020 target to reduce $\mathrm{CO} 2$ emissions from new passenger cars, https://eur-lex.europa.eu/legalcontent/EN/ALL/?uri=CELEX\%3A32014R0333.

The Federal Statistical Office, (2017). Automobilindustrie trägt 4,5\% zur Bruttowertschöpfung in Deutschland bei, Wiesbaden, https://www.destatis.de/DE/PresseService/Presse/Pressemitteilungen/2017/09/PD17 _326_811pdf.pdf?__blob=publicationFile.

Tushman, ML and CA O'Reilly, (1996). Ambidextrous Organizations: Managing Evolutionary and Revolutionary Change. California Management Review, 38(4), 8 29.

Unruh, GC, (2000). Understanding carbon lock-in. Energy Policy, 28(12), 817-830.

van Bree, B, G Verbong and GJ Kramer, (2010). A multi-level perspective on the introduction of hydrogen and battery-electric vehicles. Technological Forecasting and Social Change, 77(4), 529-540.

Wallner, HP, (1999). Towards sustainable development of industry: Networking, complexity and eco-clusters. Journal of Cleaner Production, 7(1), 49-58.

Warner, KS and M Wäger, (2019). Building dynamic capabilities for digital transformation: An ongoing process of strategic renewal. Long Range Planning, 52(3), 326-349.

Wells, P and P Nieuwenhuis, (2012). Transition failure: Understanding continuity in the automotive industry. Technological Forecasting and Social Change, 79(9), 16811692.

Ziefle, M, S Beul-Leusmann, K Kasugai and M Schwalm, (2014). Public Perception and Acceptance of Electric Vehicles: Exploring Users' Perceived Benefits and Drawbacks. In: A Marcus, ed. Design, User Experience, and Usability. User Experience Design for Everyday Life Applications and Services. Springer International Publishing, Cham, 628-639. 